Vol. 1 No. 2 September 2021 e-ISSN : 2797-3344 P-ISSN : 2797-3336

\title{
PENGARUH YOUTUBE TERHADAP HASIL BELAJAR SISWA KELAS X PADA MATA PELAJARAN TEKNIK KERJA BENGKEL DAN GAMBAR TEKNIK DI SMKN 3 SELONG LOMBOK TIMUR
}

\author{
ASRUL AGUS \\ SMKN 3 Selong, Lombok Timur, Nusa Tenggara Barat \\ Email : asrulagus19812@gmail.com
}

\begin{abstract}
ABSTRAK
Penelitian ini bertujuan untuk mengetahui bagaimana hasil dari belajar siswa pada pelajaran teknik kerja bengkel dan gambar teknik pada kelas X audio video SMKN 3 Selong, yaitu menggunakan youtube sebagai media dalam belajar. maksud dari penelitian adalah mengetahui Apakah ada pengaruh yang baik dan meningkat dengan menggunakan media pembelajaran berbasis youtube dengan pembelajaran secara Convensional terhadap hasil belajar siswa. Jenis penelitian ini merupakan penelitian kuantitatif, melalui metode eksperimen dengan satu kelas control dan satu kelas eksperimen. Proses pembelajaran dengan menggunakan youtube dapat membuat hasil belajar siswa menjadi lebih tinggi dibandingkan dengan proses pembelajaran dengan konvensional pada mata pelajaran teknik bengkel dan gambar teknik di kelas X teknik audio video. Pada kelas eksperiment dengan youtube sebagai media pembelajarannya, nilai pretest 58,68 dan nilai posttest memiliki rata-rata 83,65 dan pada kelas kontrol dengan model konvensional nilai pretest rata-rata 54,28 dan nilai posttest berada pada rata-rata 72,21. Berdasarkan dari data tersebut terlihat peningkatan yang signifikan terhadap hasil belajar siswa dengan menggunakan youtube sebagai media pembelajaran.
\end{abstract}

Kata Kunci: Youtube, Hasil belajar, Teknik kerja bengkel dan gambar teknik.

\section{ABSTRACT}

This research aims to find out how students learn on workshop engineering lessons and engineering drawings in class $\mathrm{X}$ audio video SMKN 3 Selong, by using youtube as a medium in learning. The purpose of research is to find out whether there is a good and increased influence by using youtube-based learning media with convensional learning on student learning outcomes. The learning process by using youtube can make students' learning outcomes higher compared to the conventional learning process in workshop engineering subjects and engineering images in class $\mathrm{X}$ audio video. In the experimental class with youtube as a medium of learning, the pretest score was 58.68 and the posttest score about of 83.65 and in the control class with the conventional model the average pretest was 54.28 and the average posttest score was 72.21. Based on the data, there was a significant improvement in students' learning outcomes by using youtube as a learning medium.

Keywords: Youtube, Learning results, Workshop work techniques and engineering drawings.

\section{PENDAHULUAN}

Media pembelajaran yaitu alat yang dipergunakan untuk menyalurkan pesan dari pengirim ke penerima sehingga dapat membangkitkan pikiran, perasaan, perhatian dan minat siswa dalam belajar (Sudirman, 2003). Salah satu pembaharuan bidang pendidikan, yaitu dengan menggunakan media audio visual berbasis internet (youtube), pada penelitian tentang penggunaan youtube terhadap minat dan hasil belajar siswa pada penelitian sebelumnya menyatakan adanya peningkatan secara signifikan didalam proses pembelajaran dengan menggunakan youtube, hal ini dapat dilihat dari nilai rata-rata hasil belajar siswa $>90$ dari sebelumnya <70 (Nilam : 2017). Youtube bisa diterapkan sebagai Media yang dibutuhkan saat ini. Hal ini karena youtube dapat memberikan ilmu bagi guru untuk lebih kreatif dan inovatif dalam menyajikan materi pembelajaran. Media Video youtube memungkinkan pendidik untuk meningkatkan aktifitas belajar serta lebih fokus guna memahami materi secara cepat (Moghavvemi:2018). Youtube merupakan situs video yang sangat populer saat ini."Sekitar 
Vol. 1 No. 2 September 2021 e-ISSN : 2797-3344 P-ISSN : 2797-3336

100.000 video ditonton per harinya di Youtube. dalam 24 jam terakhir ada sekitar 65.000 video baru yang diupload ke Youtube. Dimana setiap bulan, youtube disaksikan oleh 20 juta penonton dengan kisaran usia antara 12 tahun sampai 17 tahun" (Burke, Snyder, \& Rager, 2009).

Youtube bukanlah situs berbagi video pendidikan, tapi pada akhirnya Youtube memberikan layanan khusus untuk pendidikan pada tahun 2009. Keuntungan pembelajaran menggunakan video adalah adanya gambar dan suara dari sebuah peristiwa kepada pembelajar dikelas. Youtube adalah situs layanan video di internet yang sangat terkenal saat ini" (Snelson, 2011). Guru harus berupaya menciptakan pembelajaran yang menyenangkan sehingga memungkinkan peserta didik memiliki hasil belajar yang lebih baik dibandingkan pembelajaran secara konvensional. Hasil belajar merupakan skill yang dimiliki siswa setelah mereka mendapatkan kemampuan belajarnya (Sudjana : 2012).

Pada Kelas X TAV SMK Negeri 3 SELONG, hasil belajar selalu mengalami penurunan, tidak sesuai dengan harapan para guru, yang mungkin disebabkan oleh pengajaran yang bersifat konvensional, dimana guru hanya menjelaskan didepan dan siswa mendengarkan atau penggunaan media pembelajaran yang bersifat konvensional dan monoton sehingga menimbulkan rasa bosan didalam proses pembelajaran. Hal hal seperti ini membuat banyak siswa yang belum mengerti terhadap materi yang disampaikan guru secara langsung. Hasil ratarata nilai ulangan harian pada tahun ajaran 2020/2021 masih banyak berada di bawah KKM. Untuk KKM di SMKN 3 SELONG yaitu 75. penggunaan media pembelajaran yang tepat akan sangat mempengaruhi tingkat hasil belajar siswa. Nilai rata rata ulangan harian siswa dengan teknik pengajaran secara konvensional adalah 67,52. Dari data diatas dapat kita lihat bahwa minat dan hasil belajar siswa sangat rendah, sehingga hasil atau nilai yang didapat masih di bawah kriteria ketuntasan minimum atau kkm. Berdasarkan observasi kepada beberapa orang siswa kenapa hasil belajar mereka rendah, rata rata dari mereka mengatakan bahwa pembelajaran sangat monoton yang membuat mereka cepat bosan. Dan terkadang mereka tidak mengerti dengan pembelajaran tersebut. Berdasarkan hal hal tersebut, maka kami ingin mengadakan sebuah penelitian bagaimana supaya para siswa bisa mendapatkan hasil belajar yang lebih tinggi. Oleh karenanya penelitian ini menggunakan media youtube sebagai media bantu untuk para siswa agar lebih memahami pelajaran sehingga hasil belajar mereka dapat lebih meningkat atau lebih tinggi dibanding pengajaran dengan cara yang konvensional.

\section{METODE PENELITIAN}

Jenis penelitian ini merupakan penelitian kuantitatif, melalui metode eksperimen dengan satu kelas control dan satu kelas eksperimen,kelas kontrol tidak mengaplikasikan Youtube sebagai sumber belajar dan kelas .Analisis dengan statistik untuk dapat melihat bagaimana pengaruh Youtube sebagai sumber belajar, dan bagaimana Youtube berpengaruh pada hasil belajar siswa.Subjek penelitian adalah siswa TAV sebanyak 50 orang, yaitu TAV1 sebanyak 25 orang sebagai kelas kontrol dan TAV2 sebanyak 25 orang sebagai kelas eksperiment. Cara pengumpulan data pada penelitian ini meliputi: (1) Teknik Kuisioner untuk pengumpulan data yang akan untuk pengukuran ketepatan dalam memilih link Youtube sebagai sumber belajar. (2) Tes,Untuk pengumpulan data mengenai hasil belajar siswa.Untuk melihat nilai hasil belajar siswa kita gunakan uji independent sampel t-test (Ujit).Uji t Untuk melihat adakah pengaruh dari Youtube sebagai bahan sumber belajar terhadap Hasil belajar siswa. Uji t hanya satu kali, untuk melihat kesamaan pada posttest kelas eksperimen dan kelas kontrol. hipotesa dibuat berdasarkan Nilai signifikansi (sig), jika nilai sig > 0,05 maka Ho diterima (tidak terdapat hubungan), dan jika nilai sig $<0,05$ maka Ho ditolak (terdapat hubungan).

\section{HASIL DAN PEMBAHASAN}

\section{A. Hasil \\ 1. Desdkripsi data soal uji coba}


Vol. 1 No. 2 September 2021 e-ISSN : 2797-3344 P-ISSN : 2797-3336

Soal yang di ujikan terlebih dahulu dilakukan uji coba ke kelas yang terlebih dahulu sudah mempelajari materinya, yaitu dalam penelitian ini soal pretest dan posttest di ujicobakan di kelas XI SMK Negeri 1 Koto XI Tarusan. Tujuannya untuk melihat indeks pembeda ( Ip ), indeks kesukaran (Ik) dan reliabilitas tes.

Tabel 1. Klasifikasi soal uji coba

\begin{tabular}{|l|l|l|l|}
\hline NO & Ip & Ik & KET \\
\hline 1 & 2.66 & $40 \%$ & Sedang \\
\hline 2 & 2.34 & $87 \%$ & Mudah \\
\hline 3 & 2.71 & $89 \%$ & Mudah \\
\hline 4 & 2.54 & $90 \%$ & Mudah \\
\hline 5 & 2.25 & $29 \%$ & sukar \\
\hline
\end{tabular}

Tabel diatas dapat kita simpulkan bahwa soal pertanyaan sebanyak lima pertanyaan memiliki indeks pembeda dan dan kesukaran bervariasi.

\section{Deskripsi Data Hasil Belajar Menggunakan Media Youtube}

Pembelajaran mengunakan media youtube ini dilakukan pada kelas eksperimen yaitu kelas Xtav 1, sebelum dilakukan perlakuan kelas eksperimen di beri perlakuan dengan di adakan pretest dengan soal sebanyak 5 soal pertanyaan rata-rata hasil belajar 58,68 dengan jumlah 25 orang siswa. Soal tersebut dilakukan untuk mengetahui pengetahuan awal masingmasing siswa. Dan setelah diberi perlakuan maka diberi tes akhir setelah diberi perlakuan yaitu posttest dengan jumlah rata-rata hasil belajar 83,65 dengan jumlah siswa 25 siswa.

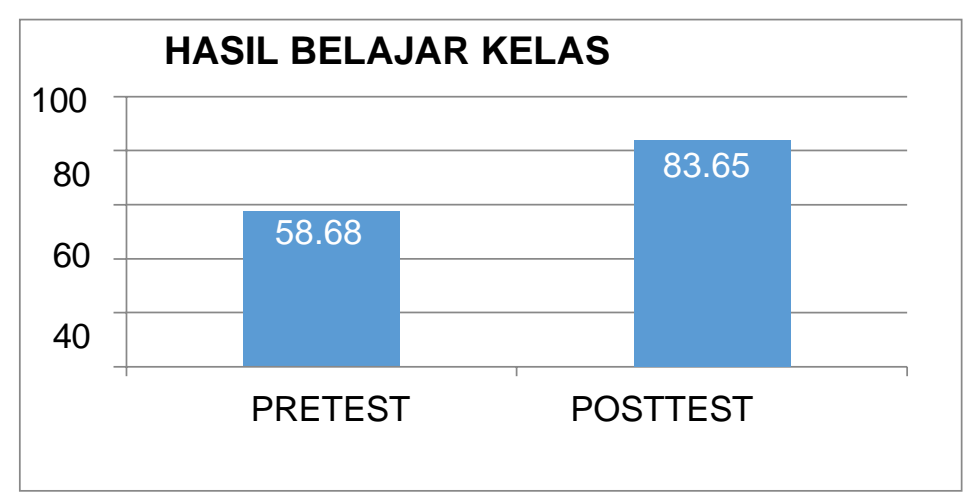

\section{Gambar 1. grafik Hasil Belajar Kelas Ekperimen}

Data diagram di atas dapat disimpulkan bahwa pembelajaran menggunakan media youtube merupakan proses pembelajaran yang dapat meningkatkan hasil belajar siswa.

3. Deskripsi Data Hasil Belajar Kontrol ( Konvensional).

Pembelajaran kelas kontrol (konvensional) pada kelas X Tav2 menggunakan model pembelajaran ceramah dan tanya jawab. Pelaksanaan pembelajaran pada kelas kontrol diawali dengan pretest dengan jumlah soal 5 butir, dengan rata-rata nilai berkisar 54,28 dengan jumlah siswa sebanyak 25 orang. Soal tersebut diberikan untuk melihat bagaimana pengetahuan awal dari masing-masing siswa. Dan setelah dilakukan perlakuan maka diberikan tes yaitu posttest dengan jumlah rata-rata hasil belajar 72,21 dengan jumlah siswa 25 orang. 
Vol. 1 No. 2 September 2021 e-ISSN : 2797-3344 P-ISSN : 2797-3336

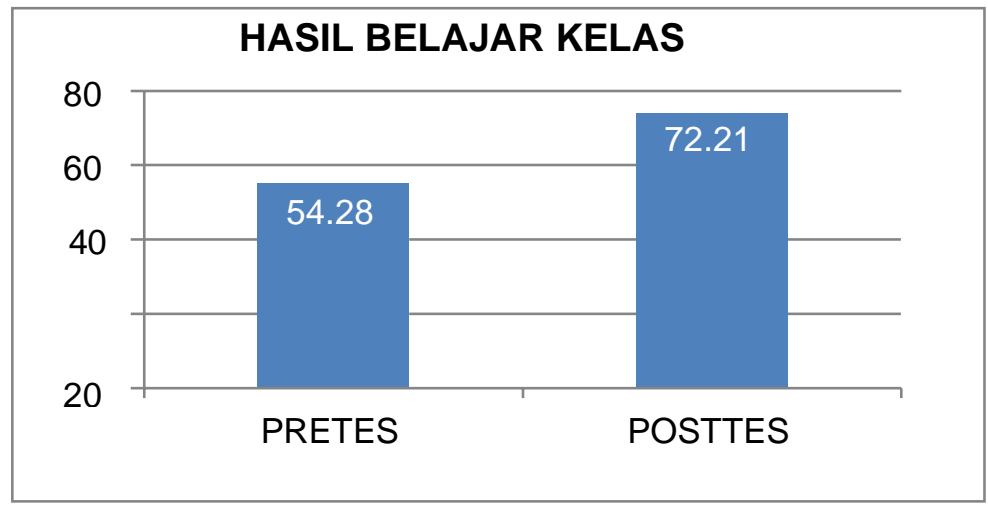

Gambar 2. Grafik hasil belajar kelas kontrol

4. Deskripsi Data Perbedaan Hasil Belajar Kelas Eksperimen (Media Youtube) dan kelas Kontrol (Konvensional).

Analisis data pada penelitian ini menggunakan beberapa pengujian prasyarat yaitu uji normalitas, uji homogenitas, dan uji t. Berikut hasil prasyarat analisis dalam penelitian ini:

\section{a. Pretest}

\section{Uji Normalitas}

Uji normalitas sebagai uji untuk mengetahui data yang dihasilkan dari penelitian berdistribusi normal atau tidak. data disebut berdistribusi normal bilamana taraf signifikasinya $\geq 0,05$, dan jika taraf signifikasinya $<0,05$ maka data dinyatakan tidak berdistribusi normal. Pada kelas eksperimen di peroleh p-value 0,585 dan kelas kontrol diperoleh p-value 0,447. Berdasarkan data tersebut dapat disimpulkan data berdistribusi normal.

Tabel 2. Hasil Uji Normalitas Posttest

\begin{tabular}{llll}
\hline No & Kelompok & p-value & Kesimpulan \\
1 & Kelas & 0,585 & Normal \\
& Eksperimen & & \\
2 & Kelas Kontrol & 0,447 & Normal \\
\hline
\end{tabular}

\section{Uji Homogenitas}

Uji homogenitas untuk mengetahui data hasil penelitian di kelas eksperimen dan kelas kontrol mempunyai nilai varian yang sama atau tidak. Disebut mempunyai nilai varian yang sama atau berbeda (homogen) jika taraf signifikannya yaitu $\geq 0,05$ dan jika taraf signifikannya yaitu $<0,05$ maka data dapat dinyatakan tidak mempunyai nilai varian yang sama/ berbeda (tidak homogen). Dari hasil perhitungan didapat p- value sebesar 0,205, hal ini berati p-value> $\alpha($ taraf nyata $=0,05)$ maka dapat disimpulkan Ho diterima atau dapat dinyatakan variansi kedua kelas homogen.

\section{Uji Hipotesis}

Uji-t pretest kelas eksperimen dan pretest kelas kontrol. Berdasarkan hasil uji Independent Sample T-test nilai tes awal (pretest), dapat diketahuii bahwa nilai thitung sebesar 1,061 dengan nilai signifikannya sebesar 0,293. Dimana thitung dibandingkan dengan t tabel, $\mathrm{t}$ hitung $<\mathrm{t}$ tabel $(1,061<2,000)$ dan nilai signifikansi $>$ Sig. $\alpha(0,293>0,05)$ maka H_0 diterima, artinya tidak terdapat perbedaan yang signifikan antara hasil belajar tes awal kelas eksperimen dan hasil belajar tes awal kelas kontrol.

\section{b. Posttest}

\section{Uji Normalitas}

Uji normalitas pada kelas eksperimen diperoleh p- value 0,203 dan pada kelas kontrol diperoleh p-value 0,335 , karena p-value pada kelas eksperimen dan kelas kontrol lebih dari taraf $\alpha=0,05$, sehingga disimpulkan data tes kedua kelas sampel berdistribusi normal. 
Vol. 1 No. 2 September 2021 e-ISSN : 2797-3344 P-ISSN : 2797-3336

Tabel 3. Hasil Uji Normalitas Posttest

\begin{tabular}{llll}
\hline No & Kelompok & p-value & Kesimpulan \\
1 & Kelas & 0,203 & Normal \\
& Eksperimen & & \\
2 & Kelas Kontrol & 0,335 & Normal \\
\hline
\end{tabular}

\section{Uji Homogenitas}

Uji homogenitas diperoleh nilai p-value sebesar 0,299, hal ini berarti p-value $>\alpha$ (taraf nyata $=0,05)$ maka dapat disimpulkan $\mathrm{HO}$ diterima atau dapat dikatakan kedua kelas sampel homogen.

\section{Uji Hipotesis}

Berdasarkan hasil uji Independent Sample T-test nilai tes akhir (posttest), dapat diketahui bahwa nilai t hitung sebesar 6,367 dengan nilai signifikannya sebesar 0,000. Dimana $\mathrm{t}$ hitung dibandingkan dengan $\mathrm{t}$ tabel, $\mathrm{t}$ hitung $>\mathrm{t}$ tabel $(6,367>2,000)$ dan nilai signifikansi < Sig. $\alpha(0,000<0,05)$ maka H0 ditolak dan Ha diterima, sehingga disimpulkan terdapat perbedaan yang signifikan antara hasil belajar kelas eksperimen dan hasil belajar kelas control pada tes akhir (posttest).

\section{B. Pembahasan}

Ada pengaruh yang signifikan antara media YouTube terhadap hasil belajar siswa pada pelajaran teknik kerja bengkel dan gambar teknik, ini dibuktikan dari nilai thitung > ttabel $(6.367>2.000)$ untuk variabel tes. Nilai signifikansi t untuk variabel tes adalah sebesar 0,000 dan nilai tersebut lebih kecil daripada probabilitas $0,05(0,000<0,05)$, sehingga dalam pengujian ini bahwa $\mathrm{H0}$ ditolak dan Ha diterima. Berdasarkan data diatas maka dapat kita katakan bahwa ada pengaruh yang positif dan signifikan antara penggunaan media YouTube sebagai media belajar dengan hasil belajar siswa pada mata pelajaran teknik kerja bengkel dan gambar teknik di kelas X teknik audio video SMK Negeri 3 Selong. melalui penelitian tersebut dapat dijelaskan bahwa dalam pembelajaran hal yang paling penting adalah hasil belajar peserta didik, karena melalui hasil belajar dapat diketahui bagaimana pencapaian peserta didik terhadap materi yang telah diajarkan. Menurut Nana Sudjana hasil belajar adalah kemampuankemampuan yang dimiliki setelah ia menempuh pengalaman belajarnya. Faktor-faktor yang mempengaruhi hasil belajar ada dua, yaitu faktor internal dan faktor eksternal. Faktor internal meliputi: faktor fisiologis, faktor psikologis, dan faktor cara belajar. Sedangkan faktor eksternal meliputi: faktor keluarga, faktor sekolah, dan faktor lingkungan.

Hasil penelitian ini mendukung hasil penelitian yang dilakukan Isna Farahsanti ( 2019 ), dalam penelitian didapatkan hasil bahwa kelas yang menggunakan media video YouTube ada pengaruh terhadap prestasi belajar matematika dibandingan kelas yang menggunakan media konvensional. Dengan teknik analisis data yang digunakan adalah uji t-test yang diolah dengan aplikasi Excel. Dari perhitungan diperoleh ttabel $=1,668$, thitung $=1,948$ karena thitung > ttabel maka H0 ditolak dengan taraf signifikan 5\%, diperoleh kesimpulan bahwa ada pengaruh media pembelajaran video YouTube terhadap prestasi belajar matematika siswa kelas X SMK Negeri 2 Sukoharjo Tahun Pelajaran 2017/2018. Adapun Adapun penelitian yang dilakukan oleh delfissannur, delimayanti, sanqua dan ambyar ( 2020 ), mengenai pengaruh yautube terhadap aktifitas dan hasil belajar siswa di smk negeri 1 kotto tarusan, menyatakan bahwa ada pengaruh yang signifikan penggunaan media youtube sebagai media pembelajaran terhadap aktifitas dan belajar siswa. melalui pemaparan diatas dapat disimpulkan bahwa penggunaan media YouTube dalam pembelajaran dapat membuat peserta didik lebih aktif, terutama dalam membaca dan memahami pelajaran. Sehingga hasil belajar siswa lebih meningkat dibandingkan dengan pembelajaran yang tanpa menggunakan media atau secara convensional.

Berdasarkan kesimpulan diatas, peran youtube untuk meningkatkan hasil belajar sangat besar terlebih di era sekarang, Youtube menjelma menjadi sumber belajar generasi milineal, terlebih dengan adanya covid 19 yang mengharuskan siswa belajara secara daring maupun luring ( tatap muka terbatas ). Sehingga youtube sangat dibutuhkan oleh peserta didik untuk 
Vol. 1 No. 2 September 2021 e-ISSN : 2797-3344 P-ISSN : 2797-3336

lebih memahami materi maupun praktik yang disampaikan guru, karena selama pandemi ini, materi dan waktu yang disampaikan guru sangatlah terbatas. Akan tetapi diera sekarang, youtube bukan lagi hanya untuk media pembelajaran saja, tetapi youtube peranannya sangat luas diantaranya youtube memungkinkan siswa untuk berekspresi dengan berbagai cara, seperti dengan memposting foto, video, klip audio, dll. Ini membantu siswa untuk mengeksplorasi bakat mereka. Peristiwa semacam itu akan mengidentifikasi bakat siswa dan memberi mereka kesempatan lebih jauh dalam kehidupan. Youtube adalah media yang sangat luas sehingga siswa dapat terhubung dengan siapapun di dunia ini. Siswa atau siapapun dapat memperoleh penghasilan yang sangat besar dengan membuat konten- konten kreatif di youtube. Bahkan Youtube di era ini sebagai media promosi yang sangat besar pengaruhnya seperti mempromosikan sebuah produk atau promosi sekolah, perguruan tinggi, kantor, pariwisata, dan juga youtube banyak di gunakan oleh organisasi baik pendidikan maupun non pendidikan sebagai wadah pembelajaran seperti webinar ataupun kegiatan non pendidikan lainnya dapat kita lihat atau acsess secara langsung atau online maupun offline sehingga kita dapat mengetahui apa yang disampaikan nara sumber. Begitu banyak kelebihan - kelebihan yang dimiliki oleh youtube yang tidak bisa disebutkan satu - persatu. Yang terpenting adalah youtube memiliki peranan yang sangat penting diera digital sekarang ini. Walaupun begitu, youtube juga banyak memiliki kekurangan- kekurangan dengan adanya konten - konten fake ataupun konten - konten yang tidak bermoral dan juga mengandung kekerasan dan lain - lain. Guru maupun orang tua harus bijak dalam menyikapi hal ini dengan memberikan pengarahan kepada peserta didik mengenai konten - konten di youtube yang boleh di lihat dan yang tidak boleh dilihat. Sehingga peserta didik dapat lebih faham dengan youtube.

\section{KESIMPULAN}

Proses pembelajaran dengan menggunakan youtube dapat membuat hasil belajar siswa menjadi lebih tinggi dibandingkan dengan proses pembelajaran dengan konvensional pada mata pelajaran teknik kerja bengkel dan gambar teknik di kelas X teknik audio video. Hal ini terlihat pada perbedaan nilai di kelas eksperimen yang memiliki nilai pretest 58,68 dan nilai posttest Memiliki rata-rata 83,65 dan proses pembelajaran menggunakan model konvensional (kontrol) dengan nilai pretest rata-rata 54,28 dan nilai posttest rata-rata sebesar 72,21. Berdasarkan dari data tersebut terjadinya peningkatan hasil belajar siswa setelah mgnggunakan youtube sebagai media pembelajaran.

\section{DAFTAR PUSTAKA}

Bulkia Rahim, dkk. 2018. Validitas Model Pembelajaran Kooperatif Tipe Jigsaw pada Mata Kuliah Teori Teknik Fabrikasi.

Delfissanur, dkk. 2020. PENGARUH MEDIA PEMBELAJARAN BERBASIS APLIKASI YOUTUBE TERHADAP AKTIFITAS DAN HASIL BELAJAR SISWA KELAS X PADA MATA PELAJARAN MESIN KONVERSI ENERGI DI SMK NEGERI 1 KOTO XI TARUSAN. Jurnal Vokasi Mekanika. (VoMek), 2(1), 53-59.

Dimyati \& Mudjiono. 2002. Belajar dan Pembelajaran. Jakarta: Asdi Mahasatya.

Isna Farahsanti. (2019). Pengaruh Media Video Youtube Terhadap Prestasi Belajar Matematika Pada Siswa Kelas X SMK Negeri 2 Sukoharjo Tahun Ajaran 2017/2018. Jurnal Pendidikan, Volume 28, Nomor 2, hal. 11

Jamil Suprihatiningrum. 2013. Strategi Pembelajaran, Teori \& Aplikasi. Jogyakarta: Ar-Ruzz Media.

Moghavvemi, S., Sulaiman, A., \& Jaafar, N. I.(2018). The International Journal of Social media as a complementary learning tool for teaching and learning : The case of youtube, 16(December 2017), 37-42.

Mohamad Nazir. (2005). Metode Penelitian. Jakarta:Ghalia Indonesia.

Nanang Martono. 2016. Metode Penilaian Kuantitatif Analisis Isi dan Analisis Data Sekunder. Jakarta: PT. Raja Grafindo Persada. 
Nilam Cahyani 2017. tentang Penggunaan Media Pembelajaran Video Youtube untuk Meningkatkan Minat dan Hasil Belajar menggambar illustrasi siswa kelas VIII E di Smp Negeri 1 Padang. Padang: UNP.

Oemar Hamalik. 2004. Psikologi Belajar dan Mengajar.Bandung: PT Sinar Baru Algensindo.

Paizaluddin, dan Ermalinda. 2014. Penelitian Tindakan Kelas (Classroom Action Research) Panduan Teoritis dan Praktis. Bandung: Alfabeta.

Rusmiwari, Sugeng. 2012. Variabel Penelitian. Tersedia pada http:www.sugengrusmiwari. blogspot.com/2012/10/variable-penelitian.html?m=1 (diakses tanggal 7 September 2014)

Sudirman. 2003. Interaksi Dan Motivasi Belajar Mengajar. Jakarta:PT.Raja Grafindo Persada. Sudjana. 2012. Penilaian Hasil dan Proses Belajar Mengajar. Bandung: Rosda Karya.

Sugiyono. 2010. Metode Penelitian Pendidikan (Pendekatan Kuantitatif, Kualitatif dan R\&D). Bandung: Alfabeta.

Suharsimi Arikunto. 2010. Prosedur Penelitian Suatu Pendekatan Praktik. Jakarta: Rineka Cipta.

Sumadi Suryabrata. 2012. Faktor-faktor yang Mempengaruhi Hasil Belajar. Jakarta: Rineka Cipta.

Sutirman. 2013. Media \& Model - model Pembelajaran Inovatif. Yogyakarta: Graha Ilmu.

Waskito, dkk. 2019. Penerapan Media Video untuk Meningkatkan Motivasi dan Hasil Belajar Siswa pada Mata Diklat Teknik Bubut Kelas XII Jurusan Teknik Permesinan SMK N 1 padang

Yufrizal, dkk. 2019. Pengaruh Media Simulator CNC 2 axis Teadap HASIL Belajar Mata Diklat CNC dasar siswa di SMK Negeri 5 Padang. Jurnal Vokasi Mekanika (VoMek), 1(1), 15-19. 